\title{
Trachea and Bronchus
}

National Cancer Institute

\section{Source}

National Cancer Institute. Trachea and Bronchus. NCI Thesaurus. Code C12961.

Trachea -The cartilaginous and membranous tube descending from the larynx and branching into the right and left main bronchi. Bronchi-The larger air passages of the lungs arising from the terminal bifurcation of the trachea. 